\title{
The Impact of Corporate Governance and Quality of Accounting Information on System Risk
}

\author{
Chih-Yi Hsiao ${ }^{1, a}$, Zhen-Qi Wang ${ }^{2, b,}{ }^{*}$ and Yu-Qien Zheng ${ }^{3, c}$ \\ ${ }^{1}$ Xiamen University Tan Kah Kee College, Fujian, China \\ ${ }^{2}$ Xiamen University Tan Kah Kee College, Fujian, China \\ ${ }^{3}$ Xiamen University Tan Kah Kee College, Fujian, China \\ acyhsiao@xujc.com, ${ }^{b}$ acc15033@stu.xujc.com, ${ }^{\text {c }}$ ubp15037@stu.xujc.com \\ ${ }^{*}$ Chih-Yi Hsiao
}

Key words: Corporate governance, Accounting information Quality, System risk

\begin{abstract}
The rapid and constant changing of global economy environment lead to great variables and challenges for the sustainable and stable operation of enterprises. The enterprise's risk includes system risk and non-system risk. System risk cannot control by itself and can only rely on effective prior defensive measures to minimize the losses. The content purpose and spiritual connotation of corporate governance are one of the important measures to lead enterprises to stable operation and sustainable development and the major information such as the financial statements of listed companies must be declared in real time according to regulations. Therefore, the information quality of the company's financial statements will also be an important key factor in resisting system risks. In this study, the impact of corporate governance and accounting information quality on system risk are explored based on a sample of Shenzhen A-shares from 2008 to 2018. To provide readers with more in-depth understanding and judgment of companies under different operating environments.
\end{abstract}

\section{Introduction}

The financial crisis in 2008 led to a huge impact. It is a classical system risk. Companies with different industry characteristics have their own system risks and different ability to against risks. Most of earlier literature showed that systematic risk is an inseparably risk, so it cannot be solved by human behaviors. However, in recent years, some scholars held opposing views that good corporate governance and the accounting information quality can moderate system risk related to financial in a certain degree. So far, few studies that link corporate governance, accounting information quality and system risk together. Therefore, this study will take A-shares on Shenzhen exchange as a sample to explore the impact of corporate governance and the quality of accounting information on system risk. Considering the probable effect lead by interaction of corporate governance and accounting information quality, this study sets the interaction of the two dimension to be independent variables. Furthermore, due to the different ability to against risk in various industry, divide all samples into five risk levels in quantile regression in order to probe in-depth the effect due from the factors on each risk levels. Thus, the empirical results should provide companies in different characteristics to formulate reasonable and practical strategies for resisting risks.

\section{Literature references}

Corporate governance and accounting information quality are related each other. Most literatures show that the corporate governance affect the quality of accounting information directly. High-quality accounting information is the foundation of corporate governance, and accounting information plays an important role in the structure of corporate governance. Effective corporate governance helps to improve the quality of accounting information (Cao, 2018). In recent literature, many scholars found that improving the quality of accounting information can reduce corporate risk (Wang et al., 2010; Huang et al. , 2012; Patton et al. , 2012; Wang, 2013; Hua, 2016; Isidro et al., 
2017). The research of Zeng (2010) and Jie \& Tang (2013) show that although systemic risk is difficult to eliminate by management, however, a good corporate governance mechanism can effectively alleviate firm's agency problems; especially the risks related financial.

\section{Method}

In this study, samples are use A-shares on Shenzhen stock exchange from 2008 to 2018 and obtain these sample figures from CSMAR financial databases. After delete the samples with incomplete data and outliers, 941 samples were obtained. This study uses the Orientation of Least Squares and Quantile Regression to compare with each other and analyze the impact of each independent variable in different risk level on system risk. In Quantile regression, and divide the system risk into five levels from $5 \%$ to $95 \%$. The regression model is as follows:

$$
\begin{aligned}
\text { beta }=\alpha_{0}+ & \alpha_{1} \text { inbo }+\alpha_{2} \text { excusal }+\alpha_{3} f c f+\alpha_{4} \text { eq }+\alpha_{5} \text { inv } \\
& +\alpha_{6} \text { ar }+\alpha_{7} \text { profit }+\alpha_{8} \text { inbord } f c f+\alpha_{9} \text { inboeq }+\alpha_{10} \text { inboinv }+\alpha_{11} \text { inboar } \\
& +\alpha_{12} \text { inboprofit }+\alpha_{13} \text { excusalfc } f+\alpha_{14} \text { excusaleq }+\alpha_{15} \text { excusalinv } \\
& +\alpha_{16} \text { excusalar }+\alpha_{17} \text { excusalprofit }+\alpha_{18} \text { assetsln }+\alpha_{19} \text { eps }+\alpha_{20} \text { ind }+\varepsilon_{0}
\end{aligned}
$$

\subsection{Variables description:}

3.1.1 Dependent variable (beta) : This study takes the beta figure as the alternative variable of the systemic risk.

\subsubsection{Independent variables}

This study takes both the number of independent directors as a percentage of total board members (inbo) and total annual salary of executive employees as a percentage of sales revenue (excusal) to be the alternative variables of corporate governance. As to accounting information quality, take five alternative variables that include free cash flow (fcf), earning quality (eq), inventory ratio (inv), account receivable ratio (ar) and profit rate (pro) as the alternative variables. Furthermore, set the interaction variables that the independent directors' percentage (inbo) and total annual salary of executive employees' (excusal) separately interact with five alternative variables for accounting information quality.

3.1.3 Control variables: This study takes firm's scale, earning per share and industry as Control variables. The firm's scale adopt the natural logarithm of firm's assets. The industry is a virtual variable, electronics industry is set as "1", and non-electronics industry is set as "0".

\section{Results}

Table 1 The empirical result of regression

\begin{tabular}{lcccccc}
\hline & $5 \%$ & $25 \%$ & $50 \%$ & $75 \%$ & $95 \%$ & OLS \\
\hline _cons & $1.535^{* * *}$ & $1.705^{* * *}$ & $1.890^{* * *}$ & $1.965^{* * *}$ & $2.160^{* * *}$ & $1.871^{* * *}$ \\
indbo & 0.103 & -0.095 & 0.038 & 0.120 & -0.210 & -0.037 \\
excusal & 8.635 & $11.567^{* *}$ & $8.953^{* *}$ & 6.998 & 0.996 & $7.2286^{* *}$ \\
fcf & -0.000 & 0.000 & 0.000 & 0.000 & -0.000 & 0.000 \\
eq & 0.001 & -0.001 & -0.001 & $-0.002^{* *}$ & $-0.002^{* * *}$ & -0.001 \\
inv & 0.007 & -0.002 & -0.019 & 0.019 & 0.064 & 0.015 \\
ar & $0.552^{* * *}$ & $0.376^{* * *}$ & $0.229^{* * *}$ & 0.105 & $0.197^{*}$ & $0.271^{* * *}$ \\
profit & -0.176 & $-0.130^{*}$ & $-0.125^{* * *}$ & $-0.259^{* * *}$ & $-0.355^{* * *}$ & $-0.171^{* * *}$ \\
indbofcf & -0.000 & -0.000 & -0.000 & -0.000 & $-0.000^{* * *}$ & $-0.000^{* *}$ \\
indboeq & $0.021^{*}$ & $0.025^{* *}$ & 0.013 & 0.006 & 0.000 & $0.020^{*}$ \\
indboinv & -0.929 & 0.385 & -0.283 & -1.542 & -1.163 & -0.617 \\
indboar & -0.684 & 0.532 & -0.288 & 0.0361 & 0.294 & 0.111 \\
indbopro & $1.991^{*}$ & $1.360^{* *}$ & $1.528^{* * *}$ & $1.218^{* * *}$ & $0.794^{* * *}$ & $1.910^{* * *}$ \\
excusalfcf & -0.000 & 0.000 & -0.000 & -0.000 & $-0.000^{* *}$ & -0.000 \\
excusaleq & -0.048 & 0.055 & 0.007 & 0.062 & 0.035 & -0.027 \\
excusalinv & 25.990 & -21.160 & $-31.675^{*}$ & $-46.926^{* *}$ & $-69.262^{* * *}$ & $-39.351^{* *}$
\end{tabular}




\begin{tabular}{lcccccc} 
excusalar & 87.733 & 30.353 & 28.327 & 24.850 & 43.140 & 33.673 \\
excusalpro & -12.471 & 1.538 & 4.143 & $37.186^{* * *}$ & $63.483^{* * *}$ & -0.108 \\
assetsln & $-0.036^{* *}$ & $-0.032^{* * *}$ & $-0.037^{* * *}$ & $-0.037^{* * *}$ & $-0.032^{* * * *}$ & $-0.035^{* * *}$ \\
eps & $-0.119^{* * *}$ & $-0.113^{* * *}$ & $-0.112^{* * *}$ & $-0.073^{* * *}$ & $-0.080^{* * *}$ & $-0.095^{* * *}$ \\
ind & 0.073 & $0.108^{* * *}$ & $0.112^{* * *}$ & $0.087^{* * *}$ & $0.077^{* *}$ & $0.097^{* * *}$ \\
\hline $\mathrm{N}$ & 941 & 941 & 941 & 941 & 941 & 941 \\
adj. R-sq & 0.214 & 0.23 & 0.222 & 0.177 & 0.161 & 0.321 \\
\hline
\end{tabular}

Note: $\mathrm{p}<=0.01$ is $* * *, 0.01<\mathrm{p}<=0.05$ is $* *, 0.05<\mathrm{p}<=0.1$ is $*$ 。

\section{Summary}

The empirical results show that the independent directors cannot work for system risk. It hints that most of independent directors are just someone who trusts or is close to by the company's top decision maker. As for the compensation of executive employees, the empirical results in OLS and lower levels in quantile regression show positively significant effect on system risk. It means that most of them tend to adopt aggressive and risky operation strategies in order to fight for their generous salary.

In accounting information quality, higher the ratio of accounts receivable, higher the system risk, and higher profit ratio, lower the system risk. It proves that the strict inspection of the evaluation and execution of sales credit is very important, as long as the company is devoted to improving its business effectiveness, maintaining good profits is a good way to counter system risks. The earning quality that operating activities as a percentage of net profit is significant negatively effect on the samples with more high risk levels. This shows that the higher risk level of enterprises should not go into speculative and high-risk derivatives or other business outside the industry, but can concentrate on their own industry, operating in their most familiar areas, the system risk will be more effective reduced than other companies.

The interaction of independent directors and free cash flow show a negatively significant effect on system risk in both the OLS and quantile regression for the higher risk level. However, the interaction with the earning quality and net profit show opposite results. It means that independent directors help to improve the accounting information quality, so that when the economic boom, they tend to take aggressive and risky strategies, then the financial performance will be good.

As for the interaction of the compensation of executive employees and the quality of accounting information, formerly the inventory ratio does not work on the system risk. However, it shows a negatively significant effect in interaction item. That is to say, in the interaction item, the impact has disappeared. Which means that the directors, supervisors and executive provide good operation strategies and improvement in the accounting information quality under the encouragement of high remuneration. As to the quantile regression in middle and high-risk samples, the interaction with net profit shows a positively significant impact on system risk, indicating that when the economy improves, most of the directors, supervisors and executives are still inclined to take actively risks under the encouragement of high salary. If by any chance of an economic downturn or occurs systemic risk, the losses to the company will also be even greater.

To sum up, in hiring independent directors, the enterprise should base on the full consideration the state of the company to hire the professional executives. As for in compensation and incentive system for employees, it is important to increase the monitoring system of supervision and inspection, in order to avoid executives from being attracted by generous remuneration and lose sight of the company's operation risks, then take the risk strategy.

\section{References}

[1] Wang, J., Political Connections, Earnings Quality and Cost of Equity Capital. China Academic Management Review. 25(10), p.80-90, 2013.

[2] Wang H., Zhu H., Tu R., The Asset Pricing of Correlation between Institutional Ownership and 
Accruals Quality-Evidence From A-share Market in China. Journal of Systems \&Management, 20 (04), p.462-471, 2011.

[3] Hua F., Corporate Idiosyncratic Risk, Information Disclosure Quality and Earnings Management-The Empirical Analysis Based on A-share Listed Companies. Journal of Shanxi University of Finance and Economics, 38(03), p.79-89, 2016.

[4] Cao M., Research on Governance Structure and Accounting Information Quality of Listed Companies. Times Finance, 711, p.244, 2018.

[5] Zeng J., The Impact of Corporate Governance on Firms'Risk-Return: Empirical Evidence from China's Listed Companies. Management Review, 22(07), p.46-54, 2010.

[6] Jie W., Tang Q., Corporate governance and risk taking - evidence from China listed companies. Research on Financial and Economic Issues, 350, p.91-97, 2013.

[7] Ashbaugh-Skaife H, Collins D W, Kinney, et al., The Effect of SOX Internal Control Deficiencies on Firm Risk and Cost of Equity, Journal of Accounting Research, 47(1), p.1-43, 2010.

[8] Huang A G, Chen C, Jha R.,Idiosyncratic Return Volatility and the Information Quality Underlying Managerial Discretion, Journal of Financial \& Quantitative Analysis, 47(4), p.873-899, 2012.

[9] Patton, Andrew J, Verardo, Michela, Does Beta Move with News? Firms-Specific Information Flows and Learning about Profitability, Review of Financial Studies, 25(9), p.2789-2839, 2012. 